Dr. José Ángel Agejas Esteban

Universidad Francisco de Vitoria

@j.agejas@gmail.com
(iD) $0000-0001-8819-1304$
- Recibido / Received 10 de julio de 2018

- Aceptado / Acepted 16 de noviembre de 2018

- Páginas / Pages De la 147 a la 161

nISSN: 1885-365X

\title{
Una aproximación ética al terror
}

An ethical approach to terror

El mundo de los videojuegos permite una forma novedosa de narrativa en la que, de todos modos, funcionan las grandes claves fundamentales que ya diseñó Aristóteles en su Retórica. Para comprender mejor el terror como género narrativo en un tipo de videojuegos, se propone una explicación que vaya de la definición del terror como pasión, a la consideración del modo en que nos afecta, para concluir con el modo de reproducir la experiencia del mismo en la narrativa de los videojuegos.

PALABRAS CLAVE: emociones, miedo, narrativas, terror, videojuegos.

The world of video games allows a novel form of narrative in which, in any case, the great fundamental keys that Aristotle designed in his Rhetoric works. In order to understand better the terror as a narrative genre in some videogames, the article proposes an explanation that starts with the definition of terror as a passion, that continues with the consideration of the way in which it affects us, and finally concludes with the way of reproducing the experience of it in the narrative of video games.

KEY WORDS: emotions, fear, narratives, terror, video games.

\section{Presentación: acerca de la forma más antigua de sentir}

Cuando se trata de comprender y explicar todos los elementos que intervienen hoy en el diseño y configuración de los videojuegos, dejando a un lado los estrictamente tecnológicos y aquellos otros derivados de la especificidad formal de una narrativa novedosa vinculada con los espacios ficcionales virtuales y la interactividad, no podemos por menos que acudir a los clásicos para explicar el papel de las pasiones en la experiencia estética que provoca la obra narrativa. En concreto, veremos aquí un género específico, el de los videojuegos de terror, directamente vinculado con una de las pasiones primarias de la experiencia humana.

La antropología de las pasiones y de las emociones que atraviesa la cultura y la filosofía occidentales es heredera de la filosofía del mundo griego en general, y de Aristóteles muy 
en particular. Sobre todo, de dos tipos de fuentes principales de su pensamiento que con frecuencia estudiamos no sólo por separado, sino desconectadas unas de otras: por un lado tenemos el tratado Sobre el alma y los libros de ética; y por otro, la Retórica y la Poética. Lo interesante de ambas fuentes es que son complementarias en dos sentidos: en la lógica que utilizan y en la dinámica que proponen.

Me explico. En el tratado De Anima y en los libros de ética, Aristóteles elabora su discurso acerca de qué y cómo es el hombre, y de cómo conseguir a partir de ahí la virtud que lo perfecciona. Se trata de una exposición teórica, académica, que sigue los parámetros del pensamiento científico, esto es, dando explicación lógica a los datos de la experiencia. Mientras que en la Poética, en cambio, Aristóteles propone una experiencia, hace una exposición vivencial de cómo provocar, suscitar y emplear las emociones del ser humano en la elaboración de las tragedias. No es un discurso teórico ni sobre el hombre ni sobre la acción, sino un manual práctico de cómo se da la experiencia integral de lo humano y cómo provocarla.

Claro que las emociones y las pasiones de las que habla son las mismas en todos, pero el modo de abordarlas, de acercarnos a ellas, y por lo tanto, de explicar cómo intervienen en la vida humana es distinto, tanto en ambos tratados, como luego en la vida de cada persona. Pero ateniéndonos a la explicación de Aristóteles y sus pautas, ¿cuál de las dos obras es más importante? Las dos. En el acercamiento que este artículo propone a una visión ética del terror, voy a tratar de hacer la integración de los dos discursos, esforzándome en mostrar cómo la explicación de qué es el terror se traduce en el modo de experimentarlo.

La riqueza de la Poética de Aristóteles es tal que, en realidad, todos los tratados de los últimos 2300 años acerca de cómo escribir teatro, novela, poesía o cine han seguido su estela con pequeñas variaciones y añadidos. Porque lo esencial ya está dicho por él. Como decía Hitchcock a propósito de su cine, lo que convierte una narración en universal no es que la temática sea más o menos comprensible por todos, sino que se dirija a las emociones primeras, y por tanto universales, del ser humano. Porque esas funcionan igual para todos y en todos los lugares del mundo: amor, odio, cólera, miedo, alegría.

He de adelantar también que mi acercamiento al mundo y lenguaje de los videojuegos es el de un neófito, por cuanto no suponen para el autor una experiencia en la que haya estado sumergido desde su infancia y juventud, como sí sucede con las generaciones posteriores. No he competido contra Supermario, ni he pegado un tiro en el Call of Duty, aunque también puedo decir que nunca me ha atrapado ningún creeper ni ningún zombi en Minecraft; ni me ha atacado ningún miembro de la facción hostil de "La Primera Civilización" en Assasin's Creed, ni me he estrellado con mi bólido tuneado en GTA. Ahora bien, de lo que estoy seguro es de que los videojuegos permiten con medios nuevos experiencias antiguas: he leído muchas historias de terror, he visto películas de miedo, he disfrutado de tragedias teatrales... Y ahí es donde nos situaremos: en comprender la experiencia que proponen estos soportes en cuanto narradores de historias, y que son las que están detrás de que algunas de ellas sean historias de terror. Una experiencia que, si mi hipótesis es cierta, está en la raíz más profunda del modo humano de ser, de la conciencia de nuestra finitud y contingencia.

En todas las culturas, que es lo mismo que decir en todas las formas humanas de estar en la realidad, ha habido narraciones míticas vinculadas con todas las pasiones humanas, sí. Básicamente porque los hombres han necesitado no sólo explicar lo que pasa, sino darse 
marcos teóricos para comprenderlo, para saber cómo integrarlo en su vida y dotar de sentido esa experiencia. El miedo y el terror son experiencias tan universales como específicamente humanas, como veremos. Y por lo mismo, de las que más han requerido, suscitado, provocado, sugerido e integrado esas narraciones míticas.

Durante un tiempo se ha tratado de explicar que esas narraciones provenían de una mentalidad infantil, temerosa, inmadura o primitiva, como si el mito fuera un estadio inferior en la escala evolutiva de la razón humana. El caso es que en pleno siglo XXI, con tecnologías avanzadísimas, esas pasiones y esos relatos míticos no sólo siguen existiendo, sino que son recreados, son renovados, son buscados... porque el mito no es un relato de una mente infantil para explicar lo que desconoce por la ciencia. El mito es una narración simbólica que nos permite integrar en una experiencia las claves necesarias para darnos razón de quiénes y cómo somos. La ciencia nos dice cómo es nuestro ADN, qué elementos químicos nos componen, etc. Lo que la ciencia no nos dice es por qué quiero ser eterno si me voy a morir, no nos explica por qué siendo capaces de ir a la luna me puede matar una bicicleta, no nos da razón suficiente de qué anhelos profundos de mi corazón tienen sentido y merecen la pena ser escuchados. En definitiva, la ciencia no nos dice, como explica Gandalf en El señor de los anillos, qué hacer con el tiempo que nos ha sido dado. La conciencia de la finitud y de que nuestro comportamiento no es un procedimiento determinado y determinista es la raíz de la experiencia del temor, del miedo, del terror.

Por eso digo que los cuentos y las historias de terror tenían, entre otras, una finalidad didáctica: la de enseñarnos a enfrentar los temores que surgen de la conciencia de la finitud. Los animales no sienten terror. Pueden percibir un peligro y huir de él. Pero no lo viven conscientemente. Esa conciencia es la que provoca el terror. Las historias de terror nos enseñan, o al menos nos provocan la experiencia desde la cual aprender y saber qué hacer.

Desde este marco de referencia inicial que da razón del enfoque crítico y antropológico en que nos situamos, voy a analizar algunas cuestiones vinculadas directamente con el terror, divididas en tres grandes apartados. El objetivo de este ensayo acerca del papel del terror en los videojuegos es primero, conocer su naturaleza; segundo, comprender cómo nos afecta; y tercero, decidir cómo lo podemos vivir y hacer que otros lo vivan. Como conclusión de todo esto, recopilaré los momentos principales de la reflexión en orden a desvelar algo acerca del sentido con que integrar la experiencia del terror como parte del modo humano de crecer y vivir nuestro desarrollo personal; a hacer del terror una experiencia significativa, capaz de aportar sentido a la existencia personal, y que no quede reducido a una mera sensación pasional.

\section{2. ¿Qué es el terror? Una pasión}

Así que lo primero será definir qué es el miedo, el terror, definirlo y ver qué elementos de la experiencia humana lo constituyen y favorecen.

El terror, más en concreto el miedo, Aristóteles lo considera una pasión. Las pasiones van acompañadas de las sensaciones de placer o dolor, y son las culpables de que los hombres seamos volubles en nuestros juicios. Esto es importante, porque precisamente lo que un buen creador de historias va a hacer (y de aquí alguna idea acerca de la ética en la creación artística) es provocar pasiones que lleven a modificar no sólo conductas, sino también ideas, 
valores, apreciaciones... Lo veremos en el tercer punto al hablar de la mímesis. Pero vayamos por partes y empecemos definiendo qué es el terror.

\subsection{Miedo, TEMOR, PÁNICO, TERROR, HORROR}

Lo primero que vamos a hacer es definir el terror, ver qué entendemos cuando usamos la palabra.

¿Hay alguna diferencia entre el terror, el miedo y el horror? Son términos cuyo significado incluye campos semánticos bastante cercanos, incluso casi sinónimos en ocasiones.

El miedo es una emoción primaria de defensa, provocada por una situación de peligro que puede ser real, o bien anticipada por la previsión, evocada por el recuerdo o producida por la fantasía. En concreto, Aristóteles lo define en su Retórica, donde habla de los usos y finalidad del lenguaje, como: «un cierto pesar o turbación, nacidos de la imagen de que es inminente un mal destructivo o penoso» (1990, 1382a).

Ya sabemos que suele ir acompañada por una reacción física, orgánica, causada por el sistema nervioso autónomo y que tiene como finalidad la de preparar el organismo para que se disponga a defenderse o a huir. En todo caso, se trata de una pasión causada por elementos de la realidad que dibujan un futuro amenazador en el que el sujeto se anticipa.

Puede tener distintos grados, y es ahí donde entran los matices aludidos por las distintas palabras con las que nos referimos a experiencias similares. Nos limitaremos a las cinco apuntadas en el título del apartado:

- Miedo: cuando la situación ante el sujeto está caracterizada por la amenaza del dolor o de su percepción. El sujeto trata de huir o alejarse de la causa del mismo.

- Temor: sería la forma menos intensa y es la provocada por situaciones que procuran al mismo tiempo, placer y dolor.

- Pánico: se da cuando el miedo es máximo y va cargado con el presentimiento de la muerte. Dificulta la organización del pensamiento y de la acción.

- Terror: es la forma extrema del miedo, con una intensidad aún mayor a la del pánico, acompañada de un deseo de escapar tan elevado que el sujeto trata de encontrar una salida inmediata, que con frecuencia consiste en encerrarse en sí mismo. La musculatura queda paralizada como una forma inconsciente que tiene el organismo de reducir su sensibilidad ante la agonía (real o imaginada).

- Horror: es un sentimiento de un miedo grande acompañado de un desprecio por lo que se presenta como repugnante y cruel. Se aplica muchas veces al objeto mismo que lo causa, por lo que decimos que «esto es un horror».

\subsection{El LUGAR DEL MIEdO COMO PASIÓN EN LA VIDA HUMANA}

Una vez que hemos visto las diferencias de matiz, tenemos que acercarnos a comprender por qué decimos que es una pasión, qué implicaciones tiene esto y qué papel juega en la vida humana.

Cuando los clásicos hablaban de pasiones no sólo utilizaban un vocabulario que ha permanecido como el modo mejor que tenemos para explicarnos las cosas, sino que también 
respondía a una experiencia cotidiana, unitaria y libre de ideologías o escuelas psicológicas empeñadas en demostrar sólo determinados presupuestos teóricos, antropológicos o ideológicos, y no tanto en dar cuenta del todo de la experiencia humana. Seguiremos la clasificación tomista cuya ventaja es que responde, por un lado, a un trabajo de observación y análisis muy cuidadoso, y por otro, a una necesidad de compresión sistemática de la totalidad y unidad de la acción humana, más allá de un empeño cientificista por explicar sólo el dato o el fragmento.

Es verdad que la psicología ha ido estudiando a lo largo del último siglo muchos elementos de la vida emocional de las personas, a menudo con modelos teóricos asimilados con la vida animal, al mismo tiempo que se ha abandonado la clasificación de las pasiones a partir del irascible y el concupiscible, dos modos de englobar los movimientos pasionales sumamente útiles y prácticos que durante siglos permitieron describir y analizar esa parte del comportamiento humano que excede a los sentidos externos y que no llega a ser del pleno dominio de la racionalidad.

La pasión es un impulso o alteración que sentimos en nuestro interior y que nos saca de nuestro estado de equilibrio provocando una alteración o agitación. Es importante retener de esta definición tres elementos:

- Primero, que es una alteración que se padece (de ahí el nombre de "pasión"), no que se provoca o se busca.

- Segundo, que hay un elemento externo que la provoca. Por lo tanto no puede confundirse con un estado de ánimo o un sentimiento, cuya causa u origen son difusos e inconcretos.

- $\quad$ Y tercero, que el sujeto que la padece ha de vérselas con ella para integrarla en su comportamiento.

No es éste el lugar ni el momento de explicar el cuadro de las pasiones y el modo en que se producen y clasifican en general, sino tan sólo de comprender lo mejor posible cómo el miedo y el terror son pasiones y qué significa eso para entenderlas adecuadamente.

La clasificación habitual que se hace siguiendo a santo Tomás (I-II, qq. 22-48) describe once pasiones, seis pertenecen al concupiscible, que son también llamadas "pasiones de conquista" (amor-odio; deseo-fuga; gozo-tristeza) y cinco al irascible, o "pasiones de combate" (esperanza-desesperación; audacia-miedo; ira), que finalmente pueden quedar reducidas a cuatro: gozo-tristeza por un lado y esperanza-miedo por otro.

Pues bien, el miedo es la principal de las pasiones de conquista que nos pone en movimiento ante la presencia de un mal que nos amenaza. $Y$ las causas del miedo pueden reducirse a dos: el amor, o si queremos, el miedo a perder el bien que anhelamos y que nos produce plenitud; y la carencia de todo lo necesario para nuestra plenitud.

Finalmente nos quedan por ver dos cuestiones importantes, e íntimamente ligadas entre sí, con el fin de caracterizar las pasiones y su lugar en la acción humana. Primero, conocer su valor moral, y segundo, conocer el grado de influencia sobre la libertad humana. Porque si hemos dicho que son energías sensibles, previas ontológicamente al ejercicio de la racionalidad, propiamente hablando no serían susceptibles de juicio moral, a no ser que la libertad tenga algo que hacer con ellas. 
En sí mismas, independientemente del comportamiento que se siga de su influjo, las pasiones no tienen carácter moral: no se pueden considerar malas, como harían los estoicos, el budismo o ciertas formas de puritanismo religioso o moral. Hay que tener en cuenta, por tanto, que surgen de manera espontánea a partir de la presencia de los objetos que las provocan. Pero una cosa es el origen de la pasión y otra muy distinta el comportamiento voluntario que el sujeto despliega a partir de la misma. $Y$ es aquí donde hay que ver hasta qué punto pueden bloquear el dominio de la inteligencia o de la voluntad para poder hablar de la moralidad, no de la pasión, sino del comportamiento subsiguiente.

En la cuestión que nos ocupa, el miedo o el terror, hay que tener en cuenta que puede surgir ante la presencia de un mal físico, de un mal imaginado, o de un mal recordado. $Y$ por otro lado, la voluntad puede actuar de dos maneras en relación con la pasión: o bien toma una decisión que se sigue de ella, dejándose influir o llevar; o bien la provoca, ya que puede mandar sobre la razón, y por lo tanto, ser causa de lo que se quiere buscar, recordar o imaginar.

Con este mapa podemos entender:

- que las pasiones tienen un papel esencial en la vida humana,

- que no son voluntarias pero tampoco ajenas a la voluntad,

- que necesitan de la inteligencia para surgir,

- que no disminuyen porque la inteligencia sea mayor o menor, ni porque el conocimiento sea mayor o menor,

- que las pasiones no tienen por sí mismas carácter moral, pero que sí es moral el comportamiento derivado de ellas.

\subsection{LA CONDICIÓN DE POSIBILIDAD PARA EXPERIMENTAR EL TERROR:}

\section{LA LATENCIA}

Pese a lo que hemos dicho a propósito del cuadro teórico de las pasiones que con tanta destreza elaboró santo Tomás, hay una reflexión contemporánea que nos permite integrar mejor el origen del miedo y su papel en la experiencia humana. Y me refiero al fenómeno de la latencia. Seguiré en esto al profesor Villacañas, quien muestra cómo es un fenómeno relevante que surge «en el cruce de un sistema infinito con un sistema finito» (2016: 4), y por tanto, se trata de la condición de posibilidad que nos permite dar cuenta y razón de la experiencia originaria del sujeto humano: «Pertenece a la forma en que una subjetividad experimenta lo real y se convierte así en una dimensión inseparable de su objeto» (2016: 5).

En pocas palabras, a esto me refería más arriba cuando decía que las pasiones tal y como las estamos viendo aquí, y más en concreto la pasión del miedo o el terror, son un fenómeno esencialmente humano. La latencia sería la dimensión constitutivamente finita de la experiencia, porque surge de algo posible, necesario, efectivo, pero no necesariamente presente.

¿Por qué es importante hablar de esta categoría? Pues, como hace Villacañas en su artículo al buscar antecedentes recientes en la filosofía contemporánea de su desarrollo, porque es en el ámbito de la filosofía del lenguaje, de la retórica, donde se empezó a atisbar 
la necesidad de explicar el modo en que son recibidos y leídos los textos, que siempre tienen una estructura temporal, y que a su vez son leídos siempre por un sujeto consciente ahora, que pone en juego su memoria y su anticipación del futuro.

En definitiva, creo que esta reflexión nos aporta una luz significativa para nuestro planteamiento. La experiencia que toda persona elabora conscientemente articula en el momento en que es vivida, la conciencia de la finitud y la posibilidad de trascendencia; o lo que es lo mismo, la memoria de las experiencias vividas dotadas de significado con la proyección a un futuro en busca de sentido. Esta es la diferencia esencial que tiene el miedo o el terror como pasión humana y la pasión animal, ya que sólo en el hombre puede surgir a partir de la experiencia y conciencia de la finitud y de la contingencia. $Y$ por tanto, cuando hablemos del modo en que nos afecta, y sobre todo, de la experiencia que por un lado se vive en la narración o que, por otro, se ha de buscar en la narración, tenemos que tener en cuenta este límite consciente que integra lo infinito en lo finito, que articula la limitación de lo que vivimos y la trascendencia de nuestra necesidad de sentido. El miedo es la experiencia originaria del límite (lo enigmático, lo inexplicable, lo extremo) y en un cierto sentido, es el origen del ejercicio de la racionalidad, y en consecuencia, de la cultura. Todo relato (con la narrativa propia de cada género o arte particular, eso no es lo esencial) ha de tener en cuenta que no sólo se dirige a un sujeto consciente de su proyección temporal, sino a un sujeto que ha de integrarla en su relato biográfico personal como eje conductor de la experiencia que propone.

No faltan autores (Serrano y Castilla, 2017) que establecen una diferencia entre el modo de sentir y proponer el terror a partir del Romanticismo (que reacciona frente a la llustración). En el análisis de muchos contemporáneos, el terror surgiría por la incapacidad del sujeto por controlar todos los elementos de la lógica establecida racionalmente, mientras que en épocas anteriores de la historia vendría provocado por la desconfianza en el poder de la razón. Esto permitiría a los narradores de historias suscitar el terror a partir de la quiebra de la lógica establecida. Creo que el modo de crear la narrativa terrorífica, en definitiva, no cambia en lo esencial, pues ya Aristóteles pauta en la Poética que en los argumentos «debe preferirse lo imposible verosímil antes que lo posible increíble. Y los argumentos no deben componerse de partes irracionales, sino que en la medida de lo posible no deben tener nada irracional» (2011, 1460a). Las narraciones utilizarán, sin duda, aquellos elementos mitológicos (vigencias y creencias en términos de Marías) que apelen a miedos ante lo potencial para convertirlos en terrores ante lo probable. Creo que esa es la clave psicológica y argumental, y la clave de la eficacia narrativa.

\section{3. ¿Cómo funciona? La afección}

Llegamos así al segundo punto, aquel en el que vamos a tratar de comprender cómo nos afectan las pasiones. Aristóteles, aunque no había llegado a formular el concepto posterior, claramente expresado por el Aquinate, de la unidad sustancial del ser humano, sí tenía claro, con todo, que las pasiones no son afecciones ni sólo del cuerpo, ni sólo del alma sensible. "Afectan" a toda la persona. Aunque tenía una biología, vista con nuestros ojos del siglo XXI, muy rudimentaria, la observación de los datos de la experiencia le permitía deducir que si bien la ira es una reacción ante un comportamiento percibido como injusto, por ejemplo, 
también nos hace sentir cómo nos hierve la sangre... Es decir, que lo espiritual, lo psicológico, lo orgánico y lo biológico estaban entrelazados en cada una de las experiencias pasionales sentidas y vividas. A esto me refería también antes cuando mencionaba que el vocabulario castellano, el modo de hablar de estos temas ha mantenido expresiones coloquiales que tienen la virtud de reflejar muy bien lo que sucede como cuando decimos: se quedó helado, se le calentó la cabeza, le cegó la ira...

\title{
3.1. El MIEDO Y SUS CONGÉNERES
}

Si uno acude al Diccionario de Autoridades encuentra que peligro se define como «el riesgo o contingencia de perder la vida o hacienda. Hablando de cosas no materiales vale riesgo o contingencia de no conseguirse o malograrse, o de caer en algún prejuicio o daño espiritual o moral».

Como señalan Marina y López Penas (1999, p. 245) en su Diccionario de los sentimientos, es casi imposible hacer una lista de las causas del miedo, de lo que puede provocar la percepción de un peligro. Aun así, se atreven a enumerar:

\begin{abstract}
La soledad, la barbarie, las catástrofes, el chantaje, la crueldad, el daño, lo imprevisto, los desastres, lo desconocido, la desdicha, la desgracia, el encarnizamiento, el ensañamiento, lo espantoso, la ferocidad, la fiereza, lo fortuito, el horror, lo ignoto, lo incierto, la inclemencia, lo inesperado, el infortunio, lo inhumano, la inmisericordia, la inseguridad, la intimidación, lo maravilloso, la monstruosidad, la perversidad, la porquería, la probabilidad, lo prodigioso, lo raro, lo repentino, el sadismo, el salvajismo, lo secreto, lo sobrenatural, lo súbito, la suciedad, lo terrible, la violencia.
\end{abstract}

Resulta muy interesante, desde el punto de vista narrativo, por tanto, comprender que, para el sujeto que es consciente de su finitud y al mismo tiempo, de su aspiración a lo infinito, todo lo imprevisto aparece de alguna manera como origen de la sensación de peligro, y por tanto, como causa del miedo como pasión.

Ya recuerda Camps (2011) que en los últimos años la inteligencia emocional ha despertado el interés por conocer mejor esa parte del comportamiento humano que, por influjo del racionalismo de la Modernidad, ha quedado relegada en la comprensión y explicación de la acción humana, cuando desde Aristóteles ya quedó suficientemente asentado que el ser humano es un complejo entramado de niveles de realidad aunados en un sujeto. Si Aristóteles en su día tuvo que separarse de su maestro Platón para poder dar cuenta de los movimientos que las pasiones introducen en todos los órdenes de la realidad, hoy, tras el paso por una Modernidad racionalista e idealista, tenemos que recorrer un itinerario similar. La vida humana, la ética como narrativa de la vida que vivimos, no es una cuestión sólo de ideas y normas, sino de experiencias que integran el sentido de todo cuanto somos y hacemos.

En el origen de las pasiones están las creencias personales, las vigencias y usos sociales, los juicios, las estimaciones, los deseos y las pretensiones que configuran el espacio social y cultural. Sin duda. Pero también hemos de ser conscientes de que la vivencia de las pasiones que procura un relato también lleva a que una persona o un grupo social pueda cambiar 
su juicio sobre la realidad, sus creencias o vigencias. En el fondo, es lo que Aristóteles aborda en la Ética de alguna manera: los conflictos entre emociones y creencias terminan provocando cambios significativos en la percepción de los valores y por tanto, aunque no son por sí mismas decisiones morales, sí que intervienen directamente. Volveremos sobre ello en el punto 4 a propósito de la mímesis.

\subsection{Productora emocional, S.A.}

Ya hemos dicho al inicio que Aristóteles considera la Retórica el complemento de la Ética porque entiende que el conocimiento del bien no es una cuestión científica desligada de la vida. Y acabamos de mostrar que nos urge desligar la comprensión de la ética, y por tanto, de la unidad de la acción humana, de la visión intelectualista que reduce el bien a una idea.

Las pasiones nos afectan, por tanto, de una manera radical, no porque en sí mismas nos den ideas distintas a las que tenemos para cambiarlas, sino porque nos aportan los elementos necesarios para comprender de manera unitaria nuestra vida. Por eso Aristóteles apostaba por la tragedia, por las narrativas como educadoras de los ciudadanos. No olvidemos que él definía al ser humano como animal político, por lo que decir que la tragedia educa al ciudadano es lo mismo que decir que educa a la persona.

Las pasiones, por tanto, afectan (en un sentido literal, es decir, producen afecciones) a nuestro modo humano de ser y estar en la realidad, y las narrativas tienen como finalidad ayudar a discernir en cada circunstancia lo que ha de ser creído, buscado, querido, o bien odiado, rechazado, evitado...

No es propio de sabios tener miedo. «El terror expulsa de mi ánimo toda sabiduría», escribe Cicerón en las Tusculanas, y Montaigne, al transcribirlo, rubrica la idea: «De nada tengo más miedo que del miedo». (...) De nuevo, pues, nos la habemos con una emoción que refleja la debilidad humana. Reacción ante lo desconocido e incierto, el miedo turba la mente, produce pesar y tristeza, e impide enfrentarse al futuro con claridad y buen sentido (Camps, 2011, p. 173).

Para concluir este apartado sobre el modo en las pasiones nos afectan y, en consecuencia, cómo han de integrarse en la experiencia humana, nos queda por ver cómo entiende Aristóteles que han de aplicarse los criterios de racionalidad en la comprensión y vivencia de las pasiones.

\subsection{LOS CRITERIOS DE RACIONALIDAD EN LAS EMOCIONES SEgún ARISTÓteles}

Aristóteles habla del modo en que han de vivirse las pasiones en sus obras morales, cuando explica que la persona ha de forjarse el carácter por medio de las virtudes, que consisten en poner el "justo medio" en relación con el objeto que las provoca. Para entenderlo bien recogeremos sus propias palabras en la Ética Nicomáquea, pues consideraba que «toda 
insensatez, cobardía, desenfreno y malhumor, cuando son excesivos, son o bien estados bestiales, o bien estados mórbidos» $(1985,1149 a)$. Vamos, que el miedo o el terror no pueden serlo ante cualquier mal. Ese justo medio no es el equilibrio entre lo que produce miedo y lo que produce arrojo, sino lo intermedio en relación con cada una de esas pasiones, en relación con el defecto y el exceso de cada una de ellas. Lo que supone el modo humano de actuar con sentido sí o sí.

¿Cuáles son los criterios de racionalidad que hemos de aplicar en las pasiones? Aristóteles nos propone cuatro:

- Si son adecuadas a los objetos y a las situaciones que las provocan.

- Son proporcionadas respecto de sus objetos intencionales o sus causas, en grado, intensidad y duración.

- Son experimentadas del modo apropiado.

- Están orientadas a fines o bienes normativamente apropiados.

Estos son los cuatro criterios conforme a los cuales evaluar el medio entre los extremos por defecto o por exceso. Y como se ve, no es sencillo, porque en el fondo, ya supone que de alguna manera la persona tiene un sentido de la proporción, del equilibrio, de la racionalidad, de lo que es apropiado. Lo que nos propone Aristóteles, por lo tanto, es que el narrador provoque esta experiencia en el espectador, en aquel que accede a la experiencia de lo humano en la obra de ficción.

En concreto, por lo que respecta al terror, dado que es una pasión que surge bajo la forma de la latencia, como hemos visto, el narrador ha de tener en cuenta esta confluencia de la finitud y la trascendencia. Es una pasión que se mueve hacia el futuro, no hacia el pasado. No implica un pesar, sino un no saber cómo actuar cuando se percibe la necesidad de hacerlo, de decidir, aunque no se conozca el resultado ni el éxito de la acción que se emprende.

\section{4. ¿Cómo lo vivimos? La mímesis}

Hemos visto hasta aquí qué significa que el terror es una pasión y cómo nos afecta. Nos queda por articular el modo en que Aristóteles nos propone que nos hagamos cargo de esa experiencia por un lado, y que construyamos las narrativas que ayuden a los demás a integrarla en su desarrollo personal.

Porque el arte de vivir bien supone el arte de sentir bien. La paideia griega consistía, básicamente, en enseñar a integrar sentimientos, emociones y acciones en la vida humana, en una narración biográfica que cada uno tiene que escribir. Por eso, como apuntaba antes, la cuestión de la mímesis tiene tanta importancia en relación con los mitos. Tal era la función de los mitos, y sobre todo, tal era la misión del tragoeda de acuerdo con la Poética de Aristóteles.

En la Ética Nicomáquea, Aristóteles afirma que las pasiones no son objeto de elogio o censura $(1985,1105 b-1106 a)$ sino sólo el modo y las circunstancias en las que las vivimos. Como hemos dicho, la formación del ciudadano, de la persona, consiste sobre todo en la formación moral, esto es, en la formación del carácter para desarrollar las virtudes, para hacer que las pasiones contribuyan a la unidad de la experiencia humana. Lo malo no es sentir terror, sino no saber cómo proyectar el futuro de nuestra vida a partir de la vivencia del miedo. Es aquí donde aparecen los elementos esenciales de la mímesis, la imitación. Veamos. 


\subsection{El MITO y LA MímeSIS}

La creación literaria tiene que provocar el placer que le es propio. No tiene que ser moralizante, pero sí moral. Esto es, no tiene que decir lo que tienes que hacer, sino provocar las pasiones de acuerdo con el modo y las circunstancias del justo medio en orden a la formación del carácter.

En la Poética hace depender la belleza de la composición de las fábulas de «una imitación de la acción y, por lo tanto, principalmente de los que actúan» (Aristóteles, 2011, 1450b). Y dado que la finalidad es lo más importante, en la obra narrativa ésta es tanto el mito como el modo en que se narra. La narración propone, por medio de la mímesis, otra mímesis. De ahí su carácter formativo. De ahí su potencia. «La imitación tiene por objeto no sólo una acción completa, sino también situaciones que inspirar temor y compasión. (...) de esta clase de acciones es imitación la tragedia, según definición» (Aristóteles, 2011, 1452a).

De modo que la mímesis tiene tres niveles:

- La narración imita una acción (provoca una experiencia)

- La palabra simboliza las afecciones del alma

- El espectador imita la acción universal reflejada

Ahora bien, ¿qué tipo de mímesis debe proponer una narración para que el terror se integre dentro de una experiencia unitaria de vida? Esta es la cuestión de base, creo. Es curioso, me parece, que no siempre se ha buscado ni proponer ni sentir el terror de la misma manera.

Por un lado, dice Aristóteles en su Poética que «la tragedia (...) logra, por medio de la piedad y el terror, la catarsis de tales pasiones» (2011, 1040b). Esto supone que la creación narrativa siempre ha de promover esta pasión para que el espectador pueda liberarse de ella.

Pero por otro, decía Hitchcock que a la gente le gusta sentir miedo cuando se siente segura. Es decir, ¿los relatos de terror son fruto de momentos de paz, solamente? ¿O también tienen la función de posibilitar comunicar vivencias buscadas que den capacidad de integrar con sentido aquellas que no son buscadas y frente a las que tenemos que saber cómo reaccionar?

Me parece interesante comprender que la mímesis como propuesta tiene una importancia que ahora está empezando a comprenderse, también a propósito de los videojuegos y los estudios que se hacen sobre las consecuencias de los mismos en el comportamiento de los niños, por ejemplo. Hasta qué punto la mímesis tiene esta función educadora lo recoge Camps, por ejemplo, cuando dice que,

Los niños sometidos a la representación ficcional de comportamientos agresivos no reaccionan de la misma forma ante el estímulo mimético. Son precisamente los niños menos imaginativos los que tienden a imitar lo que ven y trasladarlo a la realidad. Lo que significa que no saben trascender la situación e imaginar otras formas de actuar. Por el contrario, los niños habituados a los juegos de fingimiento y a las ensoñaciones, consiguen una inmersión ficcional que les permite distinguir el contexto real del ficticio y reordenar los afectos sin que les agobien (Camps, 2011, p. 317). 
Promover las vivencias de estos comportamientos educa a comprender la experiencia de lo humano, y en definitiva, la tarea y responsabilidad del creador de historias.

Nos ocuparemos de esto en los dos puntos siguientes. Primero del efecto catártico en sí mismo. Y segundo, la inclusión del terror como propuesta de vivencia capaz de aportar sentido a la vida humana en todo caso, principalmente, creo, cuando es buscada "con gusto".

\subsection{LA FINALIDAD PROPIA DE LA TRAGEDIA: LA CATARSIS}

El concepto de catarsis es utilizado por Aristóteles en muchos sentidos: purificación, expiación, purgamiento... Esto es, sentido psíquico, religioso y médico. Por lo que respecto al sentido de este trabajo, el uso que hace Aristóteles es, sobre todo, el del sentido estético-ético: por la mímesis de los actores implicados en la acción (en el videojuego esta identificación es aún mayor que en la tragedia, obviamente) el espectador ha de renovar sus afecciones interiores. No es, por tanto, una cuestión meramente emotiva, sino que el peso de la catarsis trágica recae en la vivencia racional de las afecciones provocadas por la experiencia estética.

Si dice en su Poética (2011, 1453b) que escribir tragedias es un arte mimético es porque la tragedia "imita" la vida, y posibilita un placer catártico, libera (posibilita hacernos dueños con nuestra libertad de) del temor y la compasión, precisamente porque los inspira.

El sujeto imita la acción (completa, unitaria, como veremos en la conclusión) propuesta por la imitación de lo real. Ese "completa" supone, por tanto, el sentido: planteamiento, nudo y desenlace conforme a lo humano, no sólo conforme a lo biológico o lo psicológico. Porque la compasión es ese padecer con.

La catarsis implica distancia de la mímesis: no se trata simplemente de que el sujeto imite unos comportamientos, sino de que por medio de ellos "se libere" de las pasiones, es decir, que las viva con sentido. Recordemos la frase de la Poética con que iniciamos este apartado: «la tragedia (...) logra, por medio de la piedad y el terror, la catarsis de tales pasiones» (2011, 1040b). La auténtica catarsis a mi juicio, se produce cuando el sujeto es capaz de dar el paso de la experiencia de la finitud y contingencia a la narración de su propia vida conforme con el sentido que le conduce a su plenitud. Veámoslo.

\subsection{LA BIOGRAFÍA: EL TIEMPO VIVIDO}

¿Qué hacer con el tiempo que nos ha sido dado? Aquí es donde, como he dicho más arriba, el terror cumple una función maravillosa: aprender a vivir la contingencia. El terror, el miedo, han de enseñar a integrar la propia vida. Por eso, en el fondo, nos gustan las películas de terror.

Las desgracias que provocan el terror no son cualquier desgracia, sino aquellas que hacen que uno desaparezca, se desintegre... la mayor de las cuales es, obviamente, la muerte. El miedo a pedir el bien que nos constituye es el más terrible de los miedos.

Y el arte provoca esos miedos no sólo al hacerte contemplar tu propia destrucción, sino también ante la amenaza de peligros o desgracias venideros que les pueden sobrevenir a otros, en especial, a los que uno quiere. (Aristóteles, 1990, 1382a).

Hay dos tipos de desgracias: las derivadas de las acciones de uno y las sobrevenidas. Unas las hacemos, las otras nos pasan. 
El miedo implica también distinguir lo que me pasa de los que les pasa a otros: no es una sensación subjetiva simplemente, sino que implica discernir lo que sienten los demás, lo que siente cada uno, lo que les pasa a los demás y lo que le pasa a cada uno.

Por eso el miedo implica la anticipación del peligro que lo provoca: no tememos la muerte, sino el anuncio o la previsión de la muerte. De ahí que haya una relación muy estrecha entre el miedo y el tiempo. El miedo surge porque no percibimos el tiempo como duración sino como escasez, y por tanto, deformamos la percepción del tiempo vivido, que pasa a ser un tiempo alterado. Cinco minutos esperando la llegada del asesino se nos harán eternos. El miedo viene provocado, por tanto, por lo inesperado, y eso es lo que al espectador le causa mayor turbación.

Se añade aún otro elemento a ese miedo: lo desconocido, lo que se desconoce, de lo que no se puede esperar. El sujeto no sabe el tiempo que le queda a su disposición ni lo que podrá hacer durante el mismo. Y se añade aún más: miedo a lo desconocido del inesperado: «Por lo tanto, conviene poner a los oyentes, cuando lo mejor sea que ellos sientan miedo, en la disposición de que puede sobrevenirles algún mal [...] de parte de personas de las que no cabría pensarlo» (Aristóteles, 1990, 1383a).

Se ve que todos estos elementos son fácilmente traducibles al guion de una obra de teatro, de una película o, como es el caso que nos ocupa en este artículo, de un videojuego.

Ahora, para Aristóteles el miedo ha de llevar a la compasión. Hoy no entendemos así el terror, lo vemos como el objeto mismo de la obra: el terror como género, en el fondo, no viene provocado por peligros reales (eso es el drama), sino por peligros irreales. $Y$ en este sentido el tiempo que vivimos en esa experiencia se sale de la realidad.

Hemos hecho de una pasión un tema, un género, y por tanto, sólo el terror de los actores de la acción puede provocar el terror del espectador. Por tanto hay ahora dos modos de provocar terror:

- Que el terror se manifieste como horroroso en sí mismo.

- Que el terror se manifieste de forma íntima y privada, no compartida, por lo que hay que enseñarlo pasándole a otro, porque en el fondo uno sabe que no le pasa de verdad.

¿Se puede, por tanto, ir a pasar miedo sólo por el placer de sentirlo? Entonces pierde su sentido, no nos lleva a estar precavidos ante lo inesperado.

Nöel Carroll ha estudiado a fondo el tema y expone con detalle la tesis de que las obras de terror tienen la función de suscitar lo que él denomina "terror-arte" en el público, haciendo que éste comparta las respuestas emotivas que los monstruos provocan en los personajes de ficción. No hay identificación con el personaje, pero sí asimilación de la situación en que se encuentra. Y comenta que no deja de ser curioso que el género de terror aparezca por primera vez en el siglo xvill, que es la "edad de la razón", como una especie de zona subterránea de la llustración, que permita valorar las emociones en contraste con el peso que el pensamiento ilustrado da a la razón. No cree Carroll que las repuestas del público al género de terror sean inauténticas. La emoción puede ser fingida, pero ello no impide que sea intensa. Lo cual corrobora la idea de que podemos emocionarnos por lo que sabemos que no existe y no sólo por lo que creemos que existe. existe (Camps, 2011, p. 314). 


\title{
5. Conclusión: una historia de terror
}

Tras estos apuntes, quedan en el aire un montón de posibilidades para el debate, para la reflexión, y a mi entender, sobre todo quedan posibilidades para la acción, para el quehacer artístico que es el que nos ocupa aquí.

Creo que por el desarrollo que he hecho de mis ideas, no concibo el terror de manera macabra, porque la latencia de la que hablé al inicio, nos sitúa en una experiencia de sentido, no en el absurdo. Entender el terror desde una óptica idiota, literalmente encerrada en sí misma, no aporta ninguna posibilidad de experiencias significativas. El terror no es una experiencia contra la vida, sino desde la conciencia del límite de la vida.

\begin{abstract}
Pero no solo inquieta que la ficción aterrorice sabiendo que es mentira, sino el hecho de que el terror sea atractivo: ¿por qué gusta el terror si es repulsivo? La respuesta que el autor citado [Nöel Carroll] aduce es que lo que emociona no es la referencia, sino el sentido, no el acontecimiento, sino el marco teórico en el que se inscribe. No es el monstruo lo que produce placer y lo que convierte al terror en irresistible, sino la narración en la que acontece. (...) Así, el "afecto" que os atrae es la "expectación narrativa", no el acontecimiento trágico en sí, sino el conjunto de la trama argumental (Camps, 2011, p. 314).
\end{abstract}

El problema, por tanto, no es tanto el terror, sino el marco de referencia para la vivencia del mismo. Un videojuego planteado desde el absurdo sólo tendría como sentido el morbo neurótico de generar estados de ansiedad enfermizos, desencadenantes de reacciones violentas, agresivas, y con la única finalidad de desprenderse de ellas. No digo yo que muchas de las reacciones violentas que en el mundo actual contemplamos no tengan esta perspectiva subyacente, expresión de una sociedad y cultura enfermas de sentido. Pero no pueden ser la que proponga un videojuego que busca contribuir al desarrollo de lo humano.

Una historia de terror no es una historia terrorífica: hay que crear nuevos modos de provocar experiencias posibilitadoras de un nuevo acercamiento a lo real. $\mathrm{Y}$ ahí es donde creo que los buenos videojuegos tienen un papel crucial en nuestra cultura.

Comenzamos con Aristóteles y lo retomamos al final. Voy a tratar de resumir en este párrafo todo el recorrido teórico que hemos hecho, la tesis que he tratado de mostrar a lo largo de la explicación. En su tratado De Anima, que corresponde a lo que podríamos denominar su antropología, el Estagirita habla del miedo siempre poniéndolo en relación con la virtud de la valentía, esto es, con el modo con el que el sujeto va forjando su carácter. En esto consiste el tantas veces mal comprendido "justo medio": en el desarrollo de la persona en plenitud que establece, por medio de su voluntad, el sentido para vivirlo e integrarlo en el proyecto personal que él es. La ética, en definitiva, es el modo humano de vivir que implica una experiencia, que la obra de arte bien construida de acuerdo con la poética puede favorecer. Porque la pasión es natural, pero la virtud no. 


\section{Bibliografía}

AGEJAS ESTEBAN, José Ángel (2015). "El relato audiovisual y la verificación de la experiencia moral". En: GARCÍA PAVÓN, Rafael (Ed.). Cine y Filosofía. México DF, México: Universidad Iberoamericana, pp. 113-146.

AQUINO, Tomàs de (1989). Summa Theologiae I-Ilae. Madrid, España: Editorial BAC.

ARISTÓTELES (1978). Acerca del alma. Madrid, España: Editorial Gredos.

ARISTÓTELES (1985). Ética Nicomáquea. Ética Eudemia. Madrid, España: Editorial Gredos.

ARISTÓTELES (1990). Retórica. Madrid, España: Editorial Gredos.

ARISTÓTELES (2011). Poética. Magna Moralia. Madrid, España: Editorial Gredos.

CAMPS, Victoria (2011). El gobierno de las emociones. Barcelona, España: Herder.

MARINA, José Antonio y LÓPEZ PENAS, Marisa (1999). Diccionario de los sentimientos. Barcelona, España: Anagrama.

SERRANO, Vicente y CASTILLA, Antonio (Eds). (2017). La Filosofía, el terror y lo siniestro. Madrid, España: Plaza y Valdés.

VILLACAÑAS, José Luis (2016). Latencia. La elaboración de la experiencia originaria. Diánoia, 61(76), 3-28. 